\title{
An Experimental Study on Gear Diagnosis by Using Acoustic Emission Technique
}

\author{
Şaban Ulus and Selçuk Erkaya \\ Erciyes University, Engineering Faculty, Mechatronic Engineering Department, 38039, Kayseri, Turkey
}

(Received 24 June 2014; accepted 1 January 2015)

Acoustic Emission (AE) is one of the condition monitoring and diagnosing techniques of rotating machine elements such as gears, bearings, etc. So far, many studies about fault diagnosis on gearboxes have been implemented for vibration monitoring. In addition, a great deal of research on spur gears has been done for understanding the possible gear faults by considering their acoustic characteristics. In this study, possible faults in gears were analysed by the AE technique. A single-stage gearbox system comprising both helical and spur gears was used to identify the existence of possible gear faults, such as pitting and cracking at the tooth root. Noise signal in time-domain is converted to frequency-domain by using Fast Fourier Transform (FFT). In the experimental stage, artificial faults were implemented, and some mathematical parameters such as Root Mean Square error (RMS), Crest Factor (CF), and maximum value of noise level were considered to identify the fault occurrence at the meshing gear. The results show that the $\mathrm{AE}$ technique is very effective in diagnosing the defects in a gear system by a contactless measurement. Also, compared to the other diagnostic approaches, it is clear that the gear defects can be determined at an earlier stage by the $\mathrm{AE}$ technique.

\section{NOMENCLATURE}

$\begin{array}{ll}\text { AE } & \text { Acoustic emission } \\ \text { FFT } & \text { Fast Fourier transform } \\ \text { RMS } & \text { Root mean square } \\ \text { CF } & \text { Crest factor } \\ \text { FCM } & \text { Fault condition monitoring } \\ \text { EI } & \text { Energy Index } \\ f_{\mathrm{R} 1} & \text { Rotation frequency of } 300 \mathrm{rpm} \\ f_{\mathrm{R} 2} & \text { Rotation frequency of } 500 \mathrm{rpm} \\ f_{\mathrm{R} 3} & \text { Rotation frequency of } 700 \mathrm{rpm} \\ \mathrm{dB} & \text { Decibel } \\ \text { SPL } & \text { Sound pressure level } \\ \text { BPF } & \text { Band pass filter } \\ P(t) & \text { Instantaneous sound pressure } \\ T & \text { Time interval averaging } \\ x_{\text {peak }} & \text { Maximum peak value of the signal } \\ P_{\mathrm{RMS}} & \text { Root mean square value of the sound pressure level } \\ \mathrm{CF} 0 & \text { Crest factor for no loaded condition } \\ \mathrm{CF} 1 & \text { Crest factor for 1 Nm loaded condition } \\ \mathrm{CF} 3 & \text { Crest factor for 3 Nm loaded condition } \\ \text { RMS0 } & \text { Root mean square value for no loaded condition } \\ \text { RMS1 } & \text { Root mean square value for 1 Nm loaded condition } \\ \text { RMS3 } & \text { Root mean square value for } 3 \text { Nm loaded condition }\end{array}$

\section{INTRODUCTION}

In the industry today, in order to meet consumer needs, continuity of the production and safety of the processes are of crucial importance. Continuous Fault Condition Monitoring (FCM) can reduce downtime and the total cost of products. In spite of the fact that the initial capital investment cost is high for setting the FCM system, monitoring the health of the structures has a great importance, and FCM requirements in the industry are increasing day by day. Providing a method of early detection of structural, mechanical, or electrical problems allows operators to predict where faults occurred and suggest an approximate time that the system will break down. Unexpected machine failure causes both hitches of the production schedule and increases in cost with financial loss. For this reason, Predictive Maintenance methods are very important. One of them is the Acoustic Emission (AE) technique. It requires a contactless measurement, which is an advantage for mechanical systems and their parts. Any abnormalities or defects in the machinery or equipment must be detected and analysed at an early stage to avoid major problems. Therefore, FCM of rotating machinery, such as at gears and bearings, has a crucial role in the industry, as it keeps the system in a healthy condition for maximum productivity, while detecting and diagnosing faults at an early stage. As a result, it is possible to prevent serious problems, damages, and more cost. ${ }^{1}$

It is difficult to diagnose possible gear faults such as microcracks and pitting because of their minimal effect on the system, and these kinds of faults can lead to a rapid destruction of the teeth in meshing gears. Micro-cracks and pitting in gear teeth can be a catastrophic problem resulting in tooth breakage while the system is running. Nowadays, fault diagnosis techniques for rotating machinery, such as vibration monitoring and temperature detection analysis, need a measurement technique with contact. Although vibration monitoring techniques are quite common for detecting and diagnosing faulty conditions of rotating machinery, the AE technique provides early detection of faults. ${ }^{2}$

In the last two decades, a new method for early fault diagnosis, the AE technique, has been researched and gained increasing attention. AE is defined as a matter that results in the generation of structure- or fluid-borne waves due to the rapid release of energy from localised sources within or on the surface of a material. The application of the AE technique is 
well documented in recent research, and investigators have observed some advantages over classical monitoring techniques. In gearboxes, some investigators have studied the application of AE technology for diagnostic and prognostic purposes. ${ }^{3,4}$ Other investigators analysed $\mathrm{AE}$ in detecting bending fatigue on spur gears, and noted that AE was more sensitive to crack propagation than vibration and stiffness measurements, and $\mathrm{AE}$ was also found to be more sensitive to surface damage than other fault condition monitoring techniques. ${ }^{5}$ Husin, et al. ${ }^{1}$ investigated the online fault condition monitoring techniques and noted that AE was a complimentary tool for proactive maintenance. Loutas, et al. ${ }^{6}$ employed some experimental research on fault diagnosis of gearboxes by using the AE technique. They generated some artificial defects on gears and obtained satisfactory results from AE measurements. Tan and $\mathrm{Mba}^{7,8}$ investigated the relations between the surface roughness, contact resistance, and AE levels of spur gears under partial elastohydrodynamic lubrication. These observations showed that rotation speed was more efficient than loading conditions on AE levels. They emphasized the surface roughness, rotation speed, and oil temperature for AE measurements. Energy levels of the acquired signal in the analysed time-domain and the Energy Index (EI) for statistical measurements were noted in Al-Balushi and Samanta's work. ${ }^{9}$ They also studied one helicopter gearbox by using the AE technique, and comparisons between $\mathrm{AE}$ and vibration measurements were implemented. They indicated that AE was more sensitive on early fault diagnosis than the vibration method. In their work, spur gears were used, and relations between oil film thickness, temperature, and $\mathrm{AE}$ activity were analysed. It was shown that $\mathrm{AE}$ activity was affected by surface asperity contacts more than loading condition. ${ }^{10}$

Belsak and Flasker ${ }^{11}$ investigated the crack at the tooth root of the gear, which was a common fault for gearboxes, and they used time- and frequency-domain for damaged and defect-free conditions on crack propagation. The same group ${ }^{12}$ investigated the crack size and sideband occurrence by comparing defect-free conditions by using short time frequency spectrum analysis. Fault diagnosis on a single-stage gearbox test rig with only spur gears, similar to vehicle gearboxes, was studied by using FFT and RMS for obtaining the fault characteristics of the gear. ${ }^{5}$ It was proved that the early fault detection on crack propagation was possible by AE. Combet, et al. ${ }^{13}$ studied two different waveform methods to obtain local and instantaneous averages of the signals. Local faults were recognized, and they found a diagnosing method dependent on the angle at a special frequency range. Raja Hamzah and $\mathrm{Mba}^{14}$ noted that $\mathrm{AE}$ results for spur gears were more sensitive than those for helical gears. Surface roughness and contact length was also important for the acoustic characteristics of gears. Baydar and Ball $^{15}$ used an instantenous power spectrum instead of timefrequency distribution for helical gears, and they noted that this method had an advantage not only for fixed loading conditions, but also for variable loading conditions. The same research group ${ }^{16}$ investigated the $\mathrm{AE}$ and vibration techniques on a cracked gear tooth, a broken gear tooth, and local cracks by using Wigner-Ville distribution, and they obtained results indicating that $\mathrm{AE}$ has some advantages on early fault diagnosis.
Some diagnosing techniques ${ }^{17-19}$ were implemented by using statistical measurements for helicopter gearbox transmission systems, and these methods were found to be reliable, but some of the experiments were not repeated.

In spite of the common use of vibration monitoring method in rotating machinery, up to now, classical vibration monitoring analysis techniques have not been enough for detecting incipient failures such as pitting, micro-cracks, and surface wear in gears. Machine conditions and faults such as gear failures, unbalance, shaft missallignment, and bearing defects can be monitored by using acoustic emission signals at machines' operating conditions. These signals can be used not only for growing failures, but also for incipient failures of the rotating machineries, to reduce or eleminate catastrophic damages. In this study, the AE technique was used to analyse and evaluate the gear defects on both spur and helical gears. This study was employed as an experimental research and is organized as follows: Section 2 shows the materials and methods used in this experimental study. Results obtained from the test system by using the AE technique are outlined in Section 3. And Section 4 gives a conclusion about the experimental study on the gear fault condition monitoring.

\section{MATERIALS AND METHODS}

In order to observe and analyse AE in gears, a gearbox test rig was designed. Experiments were performed on a singlestage gearbox test rig; that is, as a vehicles' transmission system. A $3 \mathrm{KW}$ electric motor was used for both spur and helical gears. A three-phase frequency inverter, Delta VFD-E, was used for the case of different working speeds. A pinion gear has 51 teeth and the driven gear has 70 teeth. The pinion gear has $f_{\mathrm{R} 1}=5 \mathrm{~Hz}, f_{\mathrm{R} 2}=8.3 \mathrm{~Hz}$, and $f_{\mathrm{R} 3}=11.67 \mathrm{~Hz}$ rotation frequencies for $300 \mathrm{rpm}, 500 \mathrm{rpm}$, and $700 \mathrm{rpm}$ rotation speeds, respectively. Also, the meshing frequencies for both pinion and driven gears are $255 \mathrm{~Hz}, 425 \mathrm{~Hz}$, and $595 \mathrm{~Hz}$ for $300 \mathrm{rpm}, 500 \mathrm{rpm}$, and $700 \mathrm{rpm}$ rotation speeds, respectively. In the experimental measurements, AE data was recorded after the following processes: (i) the gearbox system was run for about 2 hours to satisfy a working condition stability of the system, and (ii) an acoustic emission sensor was located to collect the signal for data processing.

A tool for acoustic measuring, a Bruel-Kjaer (B\&K) portable and multi-channel pulse 3560-B-X05 analyser and 4189-A021 microphone with a pre-amplifier, were used to obtain and analyse the results. An analysis programme was able to evaluate the time- and frequency-domain analysis of the obtained signals from the gearbox test rig. The analyser is able to give necessary information about AE signals by measuring Sound Pressure Level (SPL), which is a logarithmic measure of the effective sound pressure of a sound relative to a reference value. It is measured in decibels $(\mathrm{dB})$ above a standard reference level. The commonly used "zero" reference sound pressure in air is $20 \mu \mathrm{Pa}^{20}$ Sound pressure produces a signal in the microphone of the sound level meter, and the output of the signal is sent to the frequency analyser to get the character of the noise. For all that, before all of the measurements, the test environment and compatibility of the devices were checked. 


Table 1. Specification of spur and helical gears.
\begin{tabular}{|l|l|l|}
\hline \multicolumn{2}{|c|}{ SPUR GEAR SPECIFICATION } \\
\hline Parameters & Pinion & Driven \\
\hline No. of Teeth & 51 & 70 \\
\hline Module & 3 & 3 \\
\hline Shaft Angle & $90^{\circ}$ & $90^{\circ}$ \\
\hline Addendum & $3 \mathrm{~mm}$ & $3 \mathrm{~mm}$ \\
\hline Dedendum & $3.5 \mathrm{~mm}$ & $3.5 \mathrm{~mm}$ \\
\hline Pitch Circle Diameter & $153 \mathrm{~mm}$ & $210 \mathrm{~mm}$ \\
\hline Face Width & $25.1 \mathrm{~mm}$ & $25.1 \mathrm{~mm}$ \\
\hline
\end{tabular}
\begin{tabular}{|l|l|l|}
\hline \multicolumn{3}{|c|}{ HELICAL GEAR SPECIFICATION } \\
\hline Parameters & Pinion & Driven \\
\hline No. of Teeth & 51 & 70 \\
\hline Module & $3 \mathrm{~mm}$ & $3 \mathrm{~mm}$ \\
\hline Shaft Angle & $90^{\circ}$ & $90^{\circ}$ \\
\hline Addendum & $3 \mathrm{~mm}$ & $3 \mathrm{~mm}$ \\
\hline Dedendum & $3.5 \mathrm{~mm}$ & $3.5 \mathrm{~mm}$ \\
\hline Pitch Circle Diameter & $162.819 \mathrm{~mm}$ & $223.477 \mathrm{~mm}$ \\
\hline Face Width & $25.1 \mathrm{~mm}$ & $25.1 \mathrm{~mm}$ \\
\hline Direction & Right & Left \\
\hline Pressure Angle & $20^{\circ}$ & $20^{\circ}$ \\
\hline Helix Angle & $20^{\circ}$ & $20^{\circ}$ \\
\hline
\end{tabular}

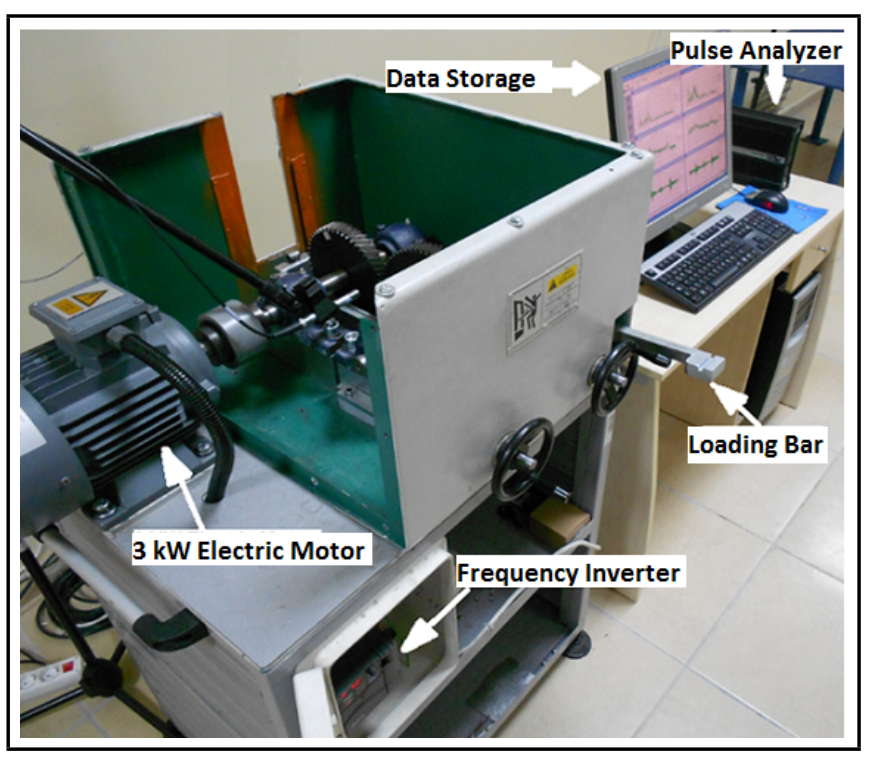

Figure 2. Gearbox Test System.

The AE signal was amplified and filtered using 20/40/60 dB, AE PREAMP/100-1200 KHz with a band pass filter (BPF). The PAC AE5A amplifier is a high performance AE system that amplifies and filters received AE signals from the preamplifier. A block diagram of the measuring system is given in Fig. 1.

Both spur and helical gears have a module of $3 \mathrm{~mm}$. Distances for the shaft center of spur gears and the shaft center of helical gears are $181.5 \mathrm{~mm}$ and $193.15 \mathrm{~mm}$, respectively. Detailed information for the gears are given in Table 1. A sliding mechanism was added to the system for setting the different distances between the shaft centers. A loading disc was attached to end of the driven gear shaft to load and break the gear system. The test rig used to measure acoustic signals is shown in Fig. 2. (a)

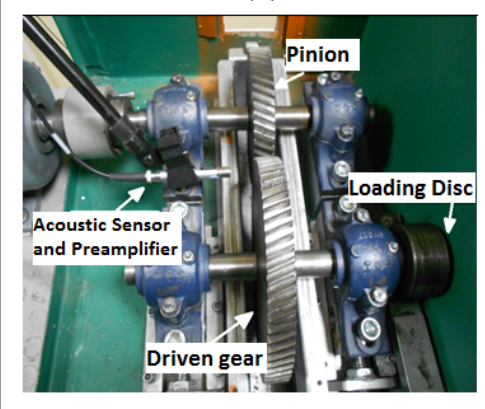

(b)

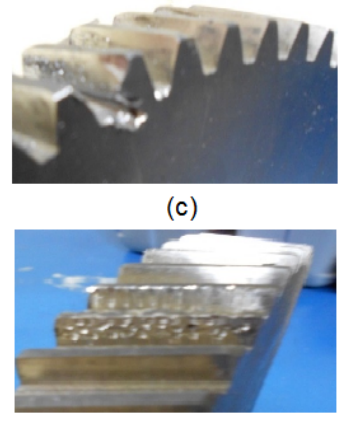

Figure 3. (a) Gearbox test system with AE sensor; (b) Cracked tooth root; (c) Pitting fault.

\subsection{Acoustic Emission Technology}

Acoustic emission is defined as the generation of transient elastic waves by the rapid release of energy within or on the surface of a material. According to Kaiser, ${ }^{21}$ crystalline solids could propagate sound under a mechanical load. Kaiser used high frequency sensors and electrical amplifiers to hear sounds in a wide range of materials under loading conditions. AE sensors are one of the most important tools for obtaining acoustic sound, and they are usually made of piezocrystalls. AE sensors detect mechanical movements or stress waves, and convert them into an electrical signal.

The main advantage of $\mathrm{AE}$ is its high sensitivity. The $\mathrm{AE}$ method is the most sensitive monitoring technique for early fault detection in rotating machine elements, especially in today's industry. AE sensors can detect sound beyond the human hearing frequency range, between $100 \mathrm{kHz}$ to $1 \mathrm{MHz}$. AE detection may not be enough for fault condition monitoring itself. The important thing with the application of the AE technique is the attenuation of the signal, and the AE sensor has to be close to source of the noise generation. Therefore, in this study, the AE sensor was placed close to the source of the noise generation; that is, at a $15 \mathrm{~cm}$ distance from the left side of the meshing point, without any contact with the gears (Fig. 3).

Signals obtained from the AE sensor are transferred to a B\&K multi-channel pulse analyser and data acquisiton system, passing through the pre-amplifier, which has a range 40 to $60 \mathrm{~dB}$.

The traditional techniques for damage detection are based on some statistical parameters of the vibration or acoustic energy. For defect-free conditions of gears, Stewart ${ }^{22}$ indicated that the regular meshing component of the signal is dominated by the mesh frequency and its harmonics. It is also observed that the sidebands about the meshing components at the rotational frequency of the gear.

Signal processing techniques (such as time and frequency analysis) and some statistical-mathematical parameters (such as RMS, CF, and average fault) were used to evaluate the faulty conditions of a material. Sound pressure generally can be expressed as the effective sound pressure for a given period of time. The effective value of sound pressure is the RMS value of the instantaneous sound pressure taken at a point over a pe- 


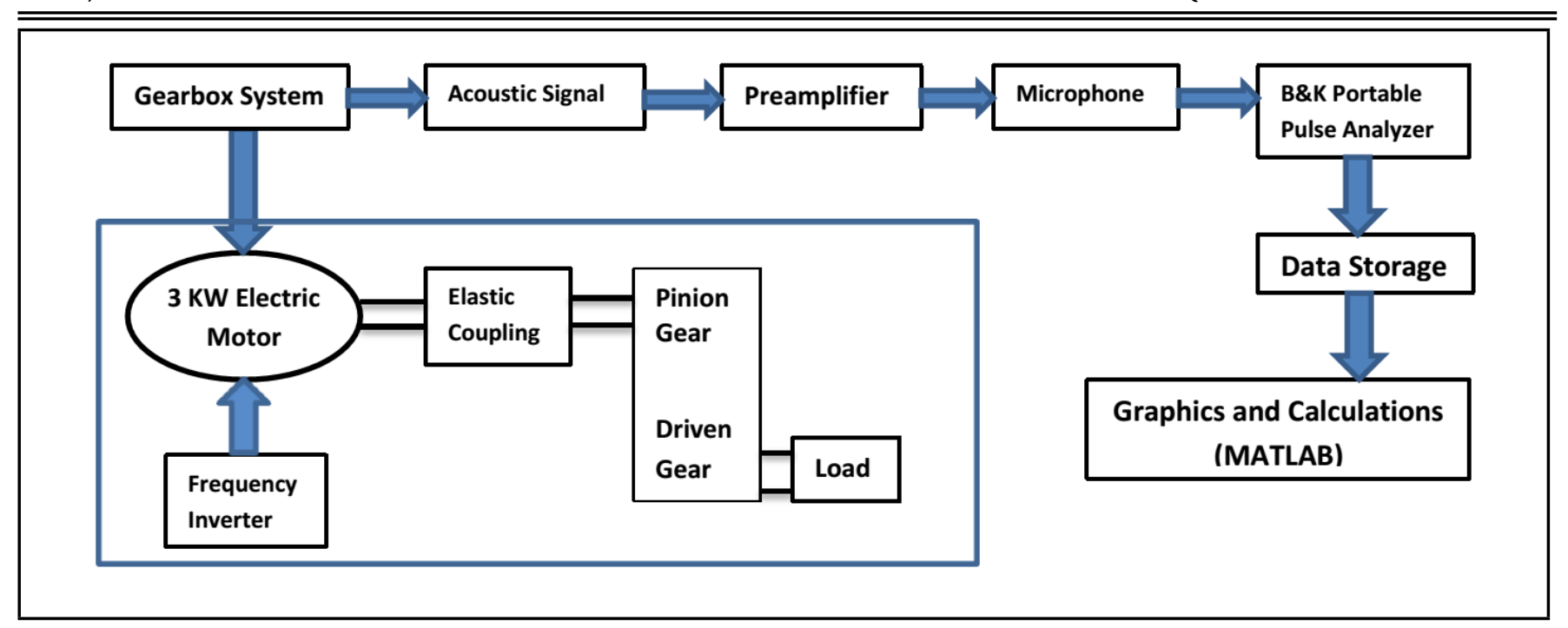

Figure 1. Block diagram of experimental measurement.

riod of time, as

$$
P_{\mathrm{RMS}}=\sqrt{\frac{1}{T} \int_{0}^{T} P^{2}(t) d t}
$$

where $P(t)$ is instantaneous sound pressure, and $T$ is the average time interval. ${ }^{20}$ The $\mathrm{CF}$ is defined as the maximum peak value of the sound pressure signal $x$, over a period of time $(T)$ divided by the RMS value of sound pressure, and is expressed by

$$
\mathrm{CF}=\frac{x_{\text {peak }}}{P_{\mathrm{RMS}}}
$$

where $P_{\mathrm{RMS}}$ is the RMS value of the sound pressure, and $x_{\text {peak }}$ is the maximum peak value of the signal. CF values are usable to understand the presence of a small amount of maximum local defects over a signal.

\section{RESULTS}

In this study, gear faults were investigated by the AE technique. Some artificial faults were formed on gears for experimental investigations. The SPL of the AE signals were measured at $300 \mathrm{rpm}, 500 \mathrm{rpm}$, and $700 \mathrm{rpm}$ shaft rotation speeds, and both helical and spur gear faults were outlined in a frequency spectrum under different loading conditions. Dry friction conditions were considered for all measurements. By considering the used running speeds, it was seen that the meshing frequency and its harmonics/sidebands were dominant between 0 and $1200 \mathrm{~Hz}$. For this reason, the frequency range of the signal in all measurements is arranged as $0 \mathrm{~Hz}-1200 \mathrm{~Hz}$. In order to eleminate the environmental noise effects, an isolated condition from other noise sources, such as room and motor noise, was implemented for the test system.

As seen in Fig. 4, AE peaks were due to the cracked tooth root that appeared in the meshing harmonics of the gear, and sidebands were also observed near the maximum fault frequency; that is, $765 \mathrm{~Hz}$ gives the third harmonic of the gear.

As shown in Fig. 4, at $300 \mathrm{rpm}$, the crest factor for the noloaded condition (CF0) was 22.07, $1 \mathrm{Nm}$ for the loaded condition (CF1) was 21.02, and $3 \mathrm{Nm}$ for the loaded condition (CF3) was 20.97. When the gears are in an undamaged state,

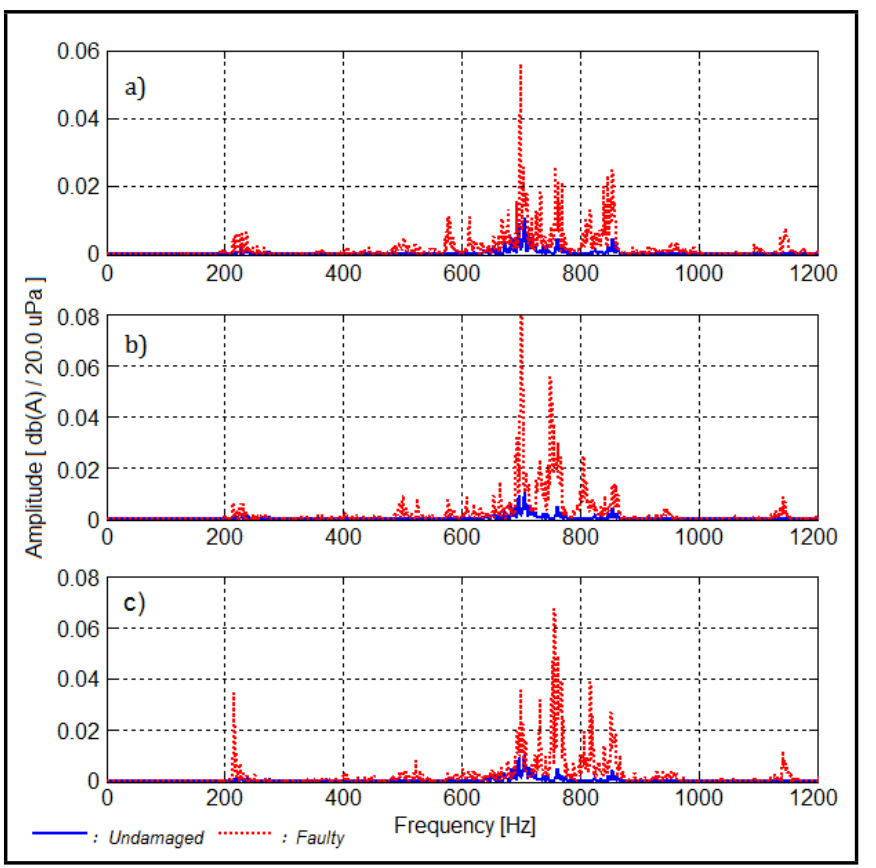

Figure 4. Cracked tooth root fault for helical gear at $300 \mathrm{rpm}$ rotation speed under (a) no loaded condition, (b) $1 \mathrm{Nm}$ loaded condition, and (c) $3 \mathrm{Nm}$ loaded condition.

the crest factor values were relatively lower than those of gears in a faulty state because of the short peaks of the undamaged state of the gear. As seen in the results, very high $\mathrm{CF}$ values resulted from high peaks. The root mean square for the noloaded condition (RMS0) was $0.043 \mathrm{~Pa}$, the root mean square for $1 \mathrm{Nm}$ for the loaded condition (RMS1) was $0.0067 \mathrm{~Pa}$, the root mean square for $3 \mathrm{Nm}$ for the loaded condition (RMS3) was $0.0069 \mathrm{~Pa}$, and those RMS values show the efficient value of faults. It can be clearly seen that there is an increase of RMS values by loading condition.

Results for $500 \mathrm{rpm}$ rotation speed are shown in Fig. 5. The obtained SPL of the gear was higher than that of 300 rpm running speed's results. Sidebands observed near the meshing harmonics related to gear tooth cracks were observed at $700 \mathrm{~Hz}$. In this running speed, $\mathrm{CF} 0, \mathrm{CF} 1$, and $\mathrm{CF} 3$ were obtained as 21.98, 20.36 and 23.77, respectively. Also, RMS0, RMS1, 


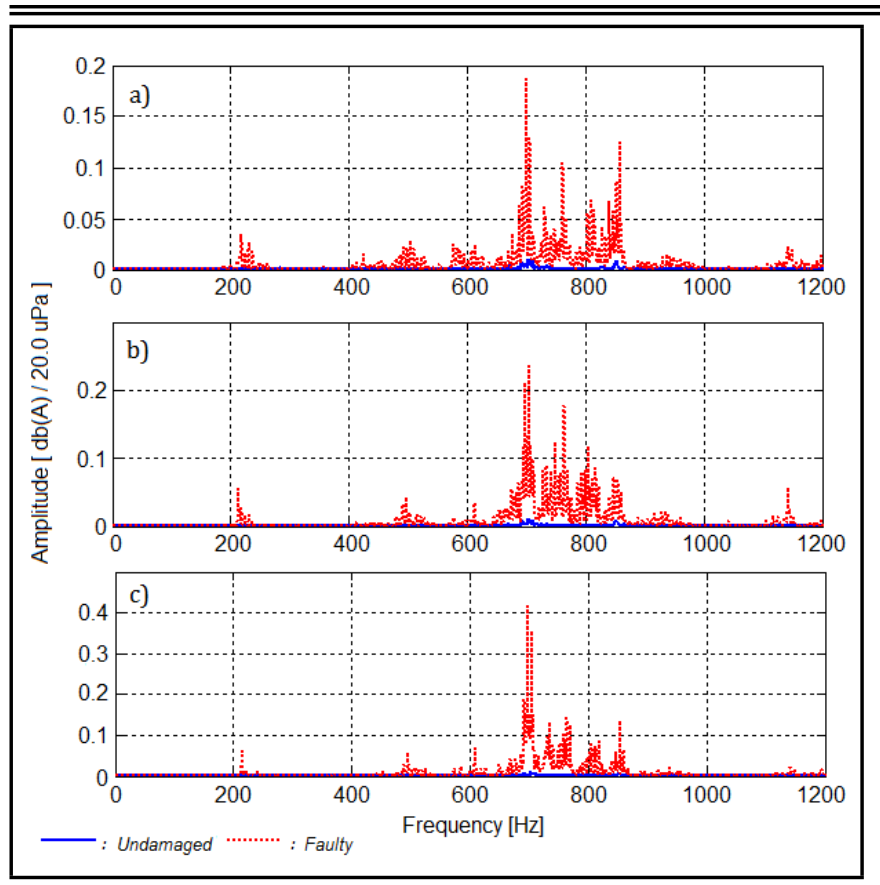

Figure 5. Cracked tooth root fault for helical gear at $500 \mathrm{rpm}$ rotation speed under (a) no loaded condition, (b) $1 \mathrm{Nm}$ loaded condition, and (c) $3 \mathrm{Nm}$ loaded condition.

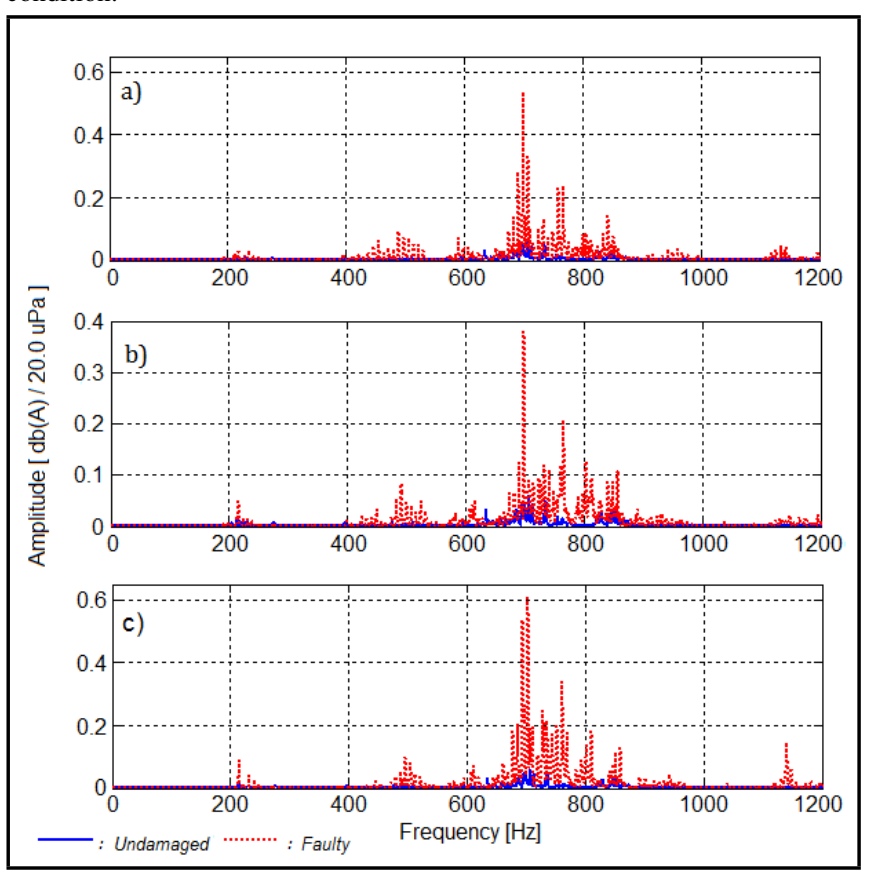

Figure 6. Cracked tooth root fault for helical gear at $700 \mathrm{rpm}$ rotation speed under (a) no loaded condition, (b) $1 \mathrm{Nm}$ loaded condition, and (c) $3 \mathrm{Nm}$ loaded condition.

and RMS3 were $0.0147,0.0222$, and $0.0267 \mathrm{~Pa}$, respectively. These RMS values show the efficient value of sound pressure in the graph, and also those RMS values are increased due to increasing loading condition.

Figure 6 gives the results of a $700 \mathrm{rpm}$ rotation speed. As outlined in this figure, SPL of the gear at $700 \mathrm{rpm}$ was higher than that of 300 and $500 \mathrm{rpm}$. The maximum value of SPL for $700 \mathrm{rpm}$ rotation speed was observed at $700 \mathrm{~Hz}$. At $700 \mathrm{rpm}$, CF0, CF1, and CF3 were 24.4, 23.39, and 22.3, respectively. Also, RMS0, RMS1, and RMS3 were obtained 0.0319, 0.0249, and $0.0463 \mathrm{~Pa}$, respectively.

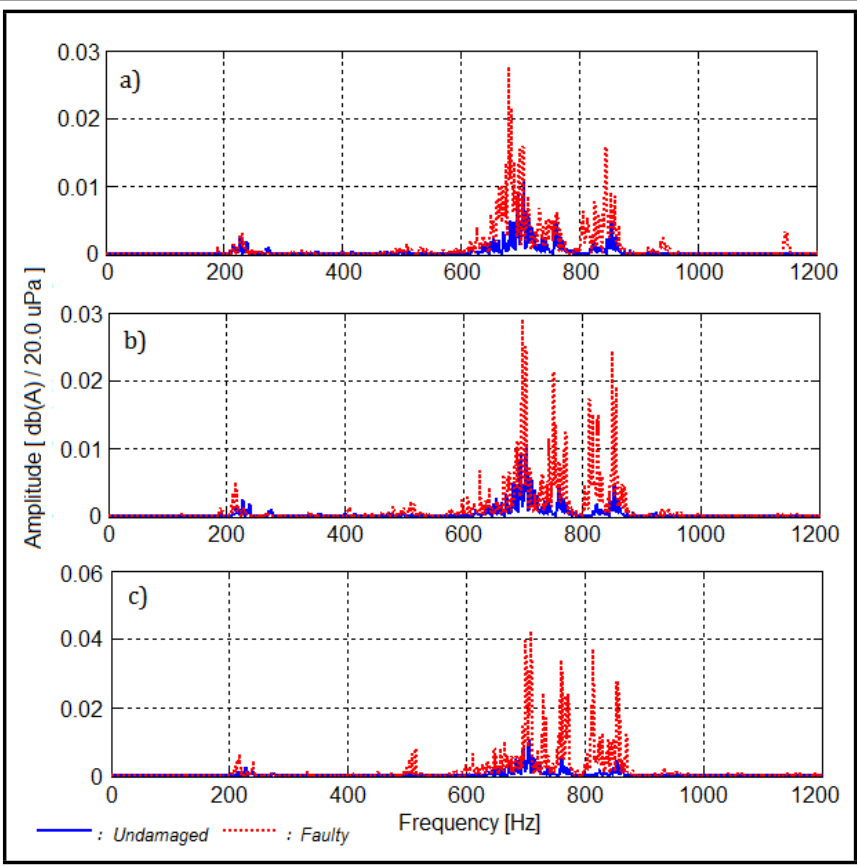

Figure 7. Pitting fault for helical gear at $300 \mathrm{rpm}$ rotation speed under (a) no loaded condition, (b) $1 \mathrm{Nm}$ loaded condition, and (c) $3 \mathrm{Nm}$ loaded condition.

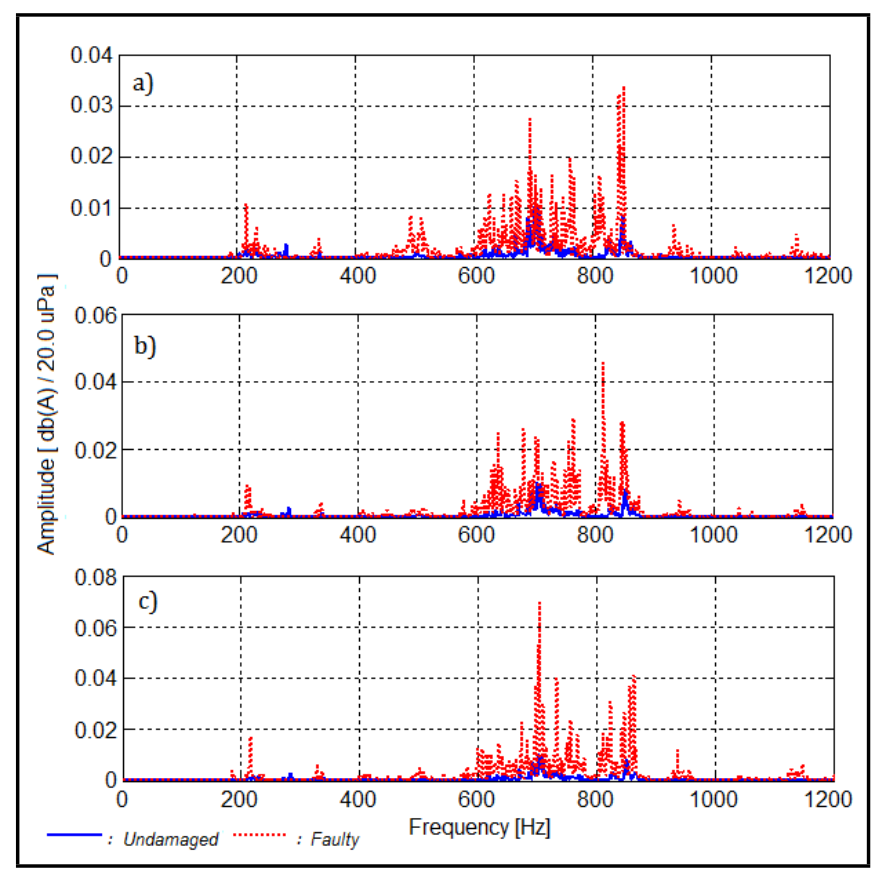

Figure 8. Pitting fault for helical gear at $500 \mathrm{rpm}$ rotation speed under (a) no loaded condition, (b) $1 \mathrm{Nm}$ loaded condition, and (c) $3 \mathrm{Nm}$ loaded condition.

For the case of pitting fault in the helical gear, the results at a speed of $300 \mathrm{rpm}$ are given in Figs. 7-9. AE peaks for both cracked tooth roots and pitting faults were seen between $700 \mathrm{~Hz}$ and $850 \mathrm{~Hz}$. However, pitting fault on the tooth surface has lower sound pressure levels than that of cracked tooth root. Statistical results for the crest factor were also given as 20.25, 19.86, and 18.8 for $\mathrm{CF} 0, \mathrm{CF} 1$, and $\mathrm{CF} 3$, respectively. RMS values were calculated as $0.0026,0.0028$, and $0.0048 \mathrm{~Pa}$ for no load, and loaded with $1 \mathrm{Nm}$ and $3 \mathrm{Nm}$, respectively.

For $500 \mathrm{rpm}$ running speed, calculated values of pitting on the helical gear tooth surface are outlined in Fig. 8 as CF0 = $18.7, \mathrm{CF} 1=20.07, \mathrm{CF} 3=21.1$, and RMS0 $=0.0036 \mathrm{~Pa}$, 


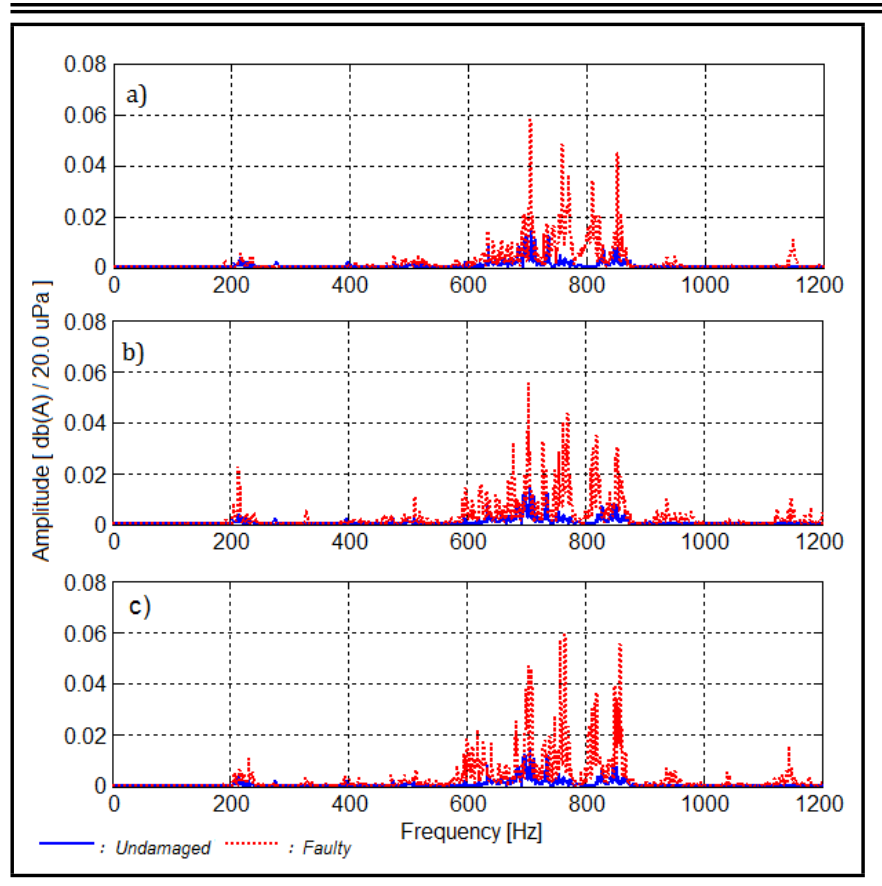

Figure 9. Pitting fault for helical gear at $700 \mathrm{rpm}$ rotation speed under (a) no loaded condition, (b) $1 \mathrm{Nm}$ loaded condition, and (c) $3 \mathrm{Nm}$ loaded condition.

\section{RMS1 $=0.0045 \mathrm{~Pa}$, and RMS3 $=0.0056 \mathrm{~Pa}$.}

In Fig. 9, at a running speed of $700 \mathrm{rpm}$, due to pitting on the helical gear tooth surface, results were calculated as $\mathrm{CF} 0=17.8, \mathrm{CF} 1=18.317$, and $\mathrm{CF} 3=18.14$, and $\mathrm{RMS0}=$ $0.0039 \mathrm{~Pa}$, RMS1 $=0.0061 \mathrm{~Pa}$, and RMS3 = 0.0071 Pa. By evaluating the results in Figs. 7-9, an increase was observed at RMS values of SPL for pitting faults due to increasing loading condition and rotational speed of the shaft. CF values are also high as in the previous results. For easy evaluations, these statistical results of CF and RMS values for a helical gear with a cracked tooth root and pitting faults are outlined in Table 2.

SPL for spur gears originated from cracked tooth roots and pitting faults are presented in Figs. 10-15. Measurement results at a running speed of $300 \mathrm{rpm}$ with and without loaded conditions are depicted in Fig. 10. AE peaks at the loaded condition are observed more clearly than those at no-loaded condition. A measurement of $765 \mathrm{~Hz}$ indicates the third harmonic of the gear at $300 \mathrm{rpm}$, and this result is based on the gear fault itself, such as clearance on the gear shaft. Sidebands near harmonic frequencies indicate faults such as a crack tooth, a broken tooth, etc. CF and RMS values for a running speed of $300 \mathrm{rpm}$ are shown in Fig. 10 as $\mathrm{CF} 0=13.49, \mathrm{CF} 1=22.23$, $\mathrm{CF} 3=23.59$, and RMS0 $=0.00051 \mathrm{~Pa}$, RMS1 $=0.0025 \mathrm{~Pa}$, and RMS3 $=0.0039 \mathrm{~Pa}$. It is clear that the loading conditions increase the RMS values.

Figure 11 indicates that the spectrum has similar character with previous result at $500 \mathrm{rpm}$. The calculated values for $\mathrm{CF}$ and RMS can be given as CF0 = 19.9, CF1 = 20.5, CF3 = 19.92 , and RMS0 $=0.0037 \mathrm{~Pa}, \mathrm{RMS} 1=0.0069 \mathrm{~Pa}, \mathrm{RMS} 3=$ $0.0068 \mathrm{~Pa}$. In Fig. 12, SPL of the cracked tooth root at $700 \mathrm{rpm}$ are presented. The mathematical results are outlined as 22.98 , 20.74 and 18.8 for CF0, CF1, and CF3, respectively. Similarly, RMS values are given as $0.0033,0.0049$, and $0.0064 \mathrm{~Pa}$ for no load, loaded with $1 \mathrm{Nm}$ and $3 \mathrm{Nm}$ conditions, respectively.

Figures $13-15$ specify the results which originated from the

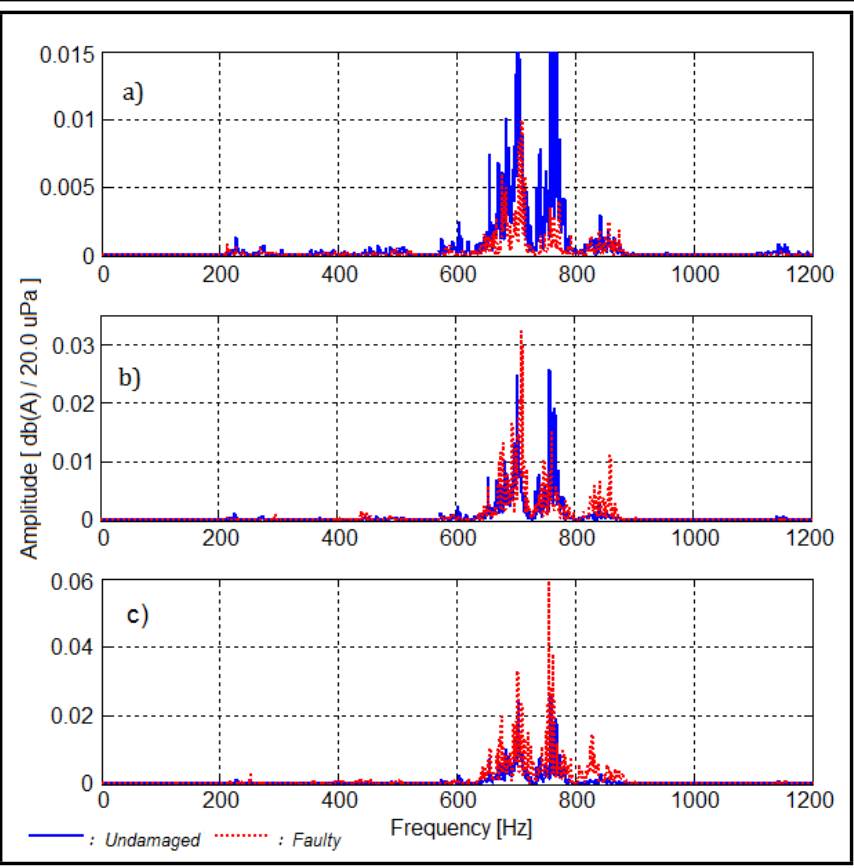

Figure 10. Cracked tooth root fault for spur gear at $300 \mathrm{rpm}$ rotation speed under (a) no loaded condition, (b) $1 \mathrm{Nm}$ loaded condition, and (c) $3 \mathrm{Nm}$ loaded condition.

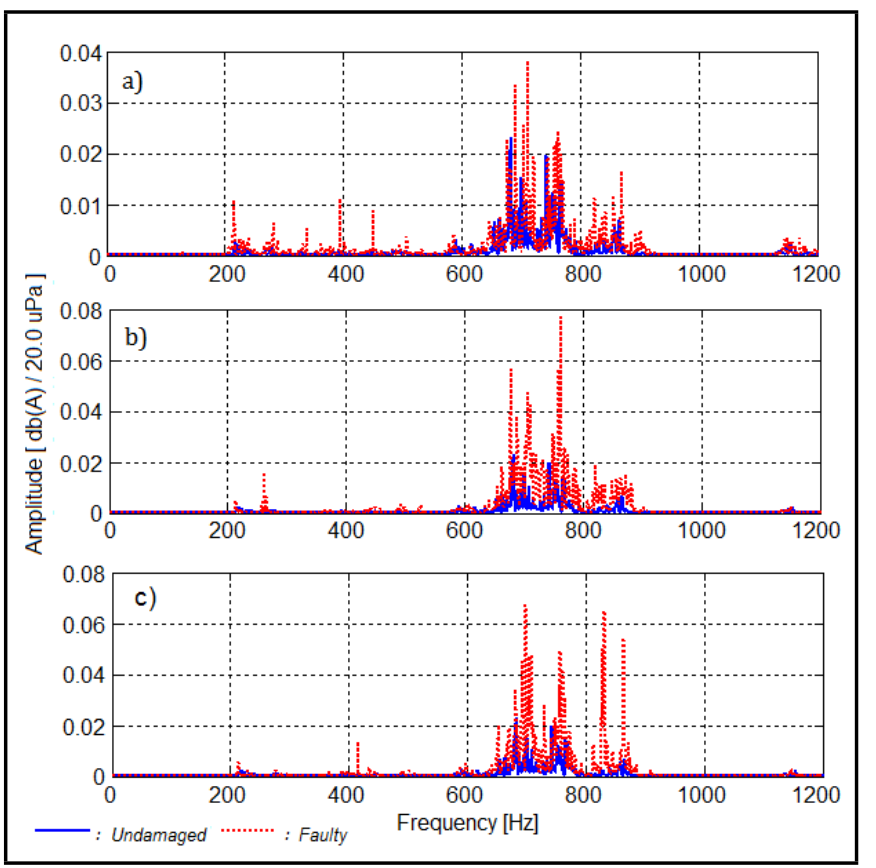

Figure 11. Cracked tooth root fault for spur gear at $500 \mathrm{rpm}$ rotation speed under (a) no loaded condition, (b) $1 \mathrm{Nm}$ loaded condition, and (c) $3 \mathrm{Nm}$ loaded condition.

pitting fault on a spur gear's tooth surface. SPL for a pitting fault on the spur gear is not so evident for $300 \mathrm{rpm}$. According to the figure, the obtained statistical results are given as $\mathrm{CF} 0=18.81, \mathrm{CF} 1=18.9$, and $\mathrm{CF} 3=20.27$, and $\mathrm{RMS} 0=$ $0.0023 \mathrm{~Pa}$, RMS1 $=0.0014 \mathrm{~Pa}$, and RMS3 = 0.0015 Pa. Figure 14 presents the results at a shaft running speed of $500 \mathrm{rpm}$. These results are more evident than those found at $300 \mathrm{rpm}$. The calculated parameters for CF and RMS are read as CF0 = $20.58, \mathrm{CF} 1=19.47, \mathrm{CF} 3=17.9$, and $\mathrm{RMS} 0=0.0051 \mathrm{~Pa}$, RMS1 $=0.0018 \mathrm{~Pa}$, and RMS3 $=0.0030 \mathrm{~Pa}$. The results at a speed of $700 \mathrm{rpm}$, as seen in Fig. 15, show that two peaks 
Table 2. RMS and CF results of helical gears.

\begin{tabular}{|c|c|c|c|c|c|c|}
\hline & \multicolumn{3}{|c|}{$\begin{array}{l}\text { HELICAL GEAR RESULTS for } \\
\text { CRACKED TOOTH ROOT FAULT }\end{array}$} & \multicolumn{3}{|c|}{$\begin{array}{l}\text { HELICAL GEAR RESULTS for } \\
\text { PITTING FAULT }\end{array}$} \\
\hline & $300 \mathrm{rpm}$ & $500 \mathrm{rpm}$ & $700 \mathrm{rpm}$ & $300 \mathrm{rpm}$ & $500 \mathrm{rpm}$ & $700 \mathrm{rpm}$ \\
\hline RMS0 & 0.043 & 0.0147 & 0.0319 & 0.0026 & 0.0036 & 0.0039 \\
\hline RMS1 & 0.0067 & 0.0222 & 0.0249 & 0.0028 & 0.0045 & 0.0061 \\
\hline RMS3 & 0.0069 & 0.0267 & 0.0463 & 0.0048 & 0.0056 & 0.0071 \\
\hline CF0 & 22.07 & 21.98 & 24.4 & 20.25 & 18.7 & 17.8 \\
\hline CF1 & 21.02 & 20.36 & 23.39 & 19.86 & 20.07 & 18.317 \\
\hline CF3 & 20.97 & 23.77 & 22.3 & 18.8 & 21.1 & 18.14 \\
\hline
\end{tabular}

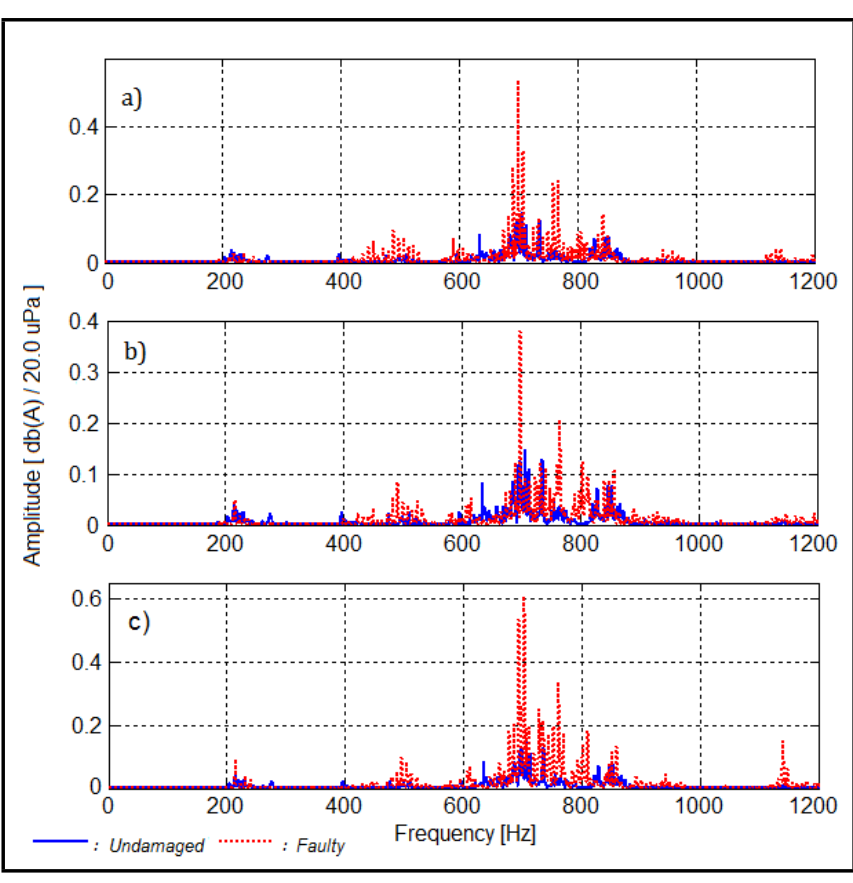

Figure 12. Cracked tooth root fault for spur gear at $700 \mathrm{rpm}$ rotation speed under (a) no loaded condition, (b) $1 \mathrm{Nm}$ loaded condition, and (c) $3 \mathrm{Nm}$ loaded condition.

are observed as sidebands of the meshing harmonics, and are evident without any loading. As confirmed from the figure, $\mathrm{CF}$ and $\mathrm{RMS}$ values are calculated as $\mathrm{CF} 0=27.93, \mathrm{CF} 1=22.6$, $\mathrm{CF} 3=20.8$, and RMS0 $=0.0275 \mathrm{~Pa}$, RMS1 $=0.0019 \mathrm{~Pa}$, and RMS3 $=0.0039 \mathrm{~Pa}$. CF values indicate the peak level of the fault signal. A load at the gear wheel plate increases RMS values. For easy evaluations, the statistical results of CF and RMS values for a spur gear with a cracked tooth root and pitting faults are outlined in Table 3.

When analysing the results, it can be seen that CF and RMS values are related to damage severity in the gear unit. All CF values indicate the damage with regard to its high value, as discussed in work by Tan and Mba. ${ }^{8}$ RMS values show the efficient value of the signal between undamaged and faulty conditions. From the results at the given operating time, it can be seen that the greater the applied running speed, the greater the AE RMS value. Higher running speeds and loading conditions affect the RMS level of the signal increasingly. Besides all these measurements, the maximum and average values of the signals are increased. In addition, the measurements were carried out after the assembly of different gear types with different faults in the experimental test rig. Measurements were repeated five times for every gear type and condition. As seen from Fig. 10 - that is, a cracked tooth root fault for a spur gear at a rotation speed of $300 \mathrm{rpm}$ - the dominant effect arises

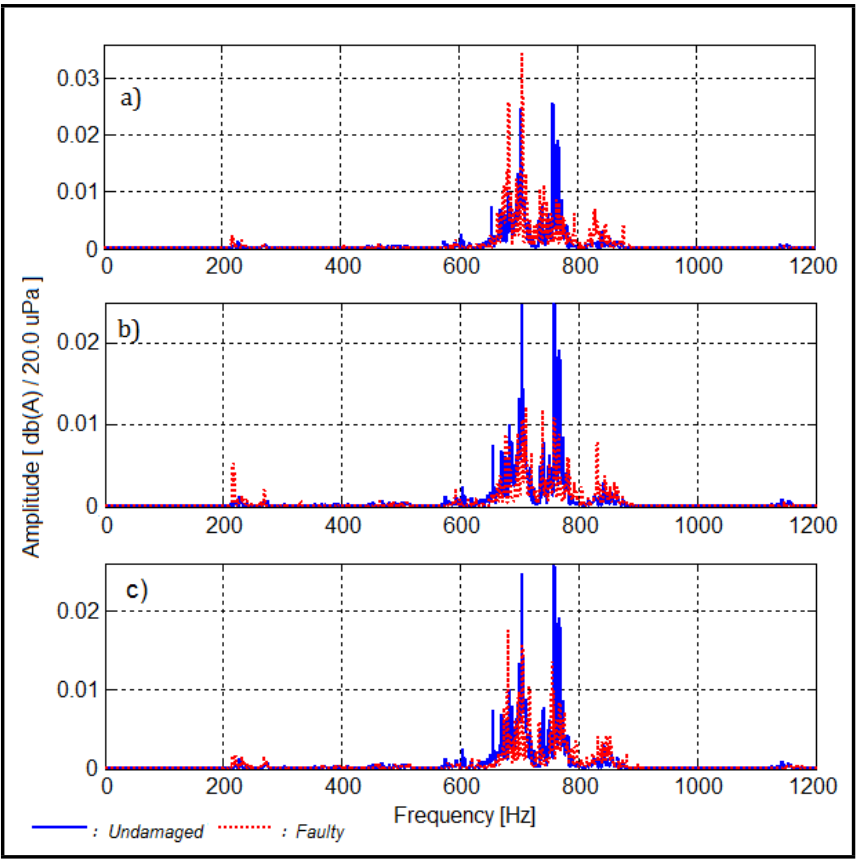

Figure 13. Pitting fault for spur gear at $300 \mathrm{rpm}$ rotation speed under (a) no loaded condition, (b) $1 \mathrm{Nm}$ loaded condition, and (c) $3 \mathrm{Nm}$ loaded condition.

from the undamaged condition of spur gear. This problem is probably due primarily to sensitivity losses of assembly conditions, such as gear meshing characteristics, looseness, imperfect alignments of the shaft, etc. ${ }^{8,10,16}$ By comparison with the RMS results, CF values have an irregular change in case of loading and running speed changes of the system. As shown in Eq. (2), the reason for this irregularity can arise from the highest $\mathrm{AE}$ peak taken into account in the signal relative to RMS. $^{23,24}$ In detecting and diagnosing fault signals, RMS results have been more indicative than $\mathrm{CF}$ values.

\section{CONCLUSION}

In this study, AE results obtained from the gearbox test system were analysed under different running speeds and loading conditions for both spur and helical gears. AE data was taken in time domain and converted to frequency domain by using FFT in order to clearly understand the occurrence of the fault location and its source.

Measurements were implemented by using an acoustic sensor near the meshing points of the gears without any contact to the test system. The artificially created gear damages, such as pitting and cracks at the tooth roots, were apparent in the $\mathrm{AE}$ graphs. At the meshing frequencies, AE peaks indicate the normal condition of the gear. AE peaks observed near the meshing harmonics, which are called sidebands, indicate the gear 
Table 3. RMS and CF results of spur gears.

\begin{tabular}{|l|l|l|l|l|l|l||}
\hline \multirow{2}{*}{} & \multicolumn{3}{|c|}{$\begin{array}{c}\text { SPUR GEAR RESULTS for } \\
\text { CRACKED TOOTH ROOT FAULT }\end{array}$} & \multicolumn{3}{c|}{$\begin{array}{c}\text { SPUR GEAR RESULTS for } \\
\text { PITTING FAULT }\end{array}$} \\
\cline { 2 - 7 } & $300 \mathrm{rpm}$ & $500 \mathrm{rpm}$ & $700 \mathrm{rpm}$ & $300 \mathrm{rpm}$ & $500 \mathrm{rpm}$ & $700 \mathrm{rpm}$ \\
\hline RMS0 & 0.00051 & 0.0037 & 0.0033 & 0.0023 & 0.0051 & 0.0275 \\
\hline RMS1 & 0.0025 & 0.0069 & 0.0049 & 0.0014 & 0.0018 & 0.0019 \\
\hline RMS3 & 0.0039 & 0.0068 & 0.0064 & 0.0015 & 0.0030 & 0.0039 \\
\hline CF0 & 13.49 & 19.9 & 22.98 & 18.81 & 20.58 & 27.93 \\
\hline CF1 & 22.23 & 20.5 & 20.74 & 18.9 & 19.47 & 22.59 \\
\hline CF3 & 23.59 & 19.92 & 18.8 & 20.27 & 17.9 & 20.8 \\
\hline
\end{tabular}

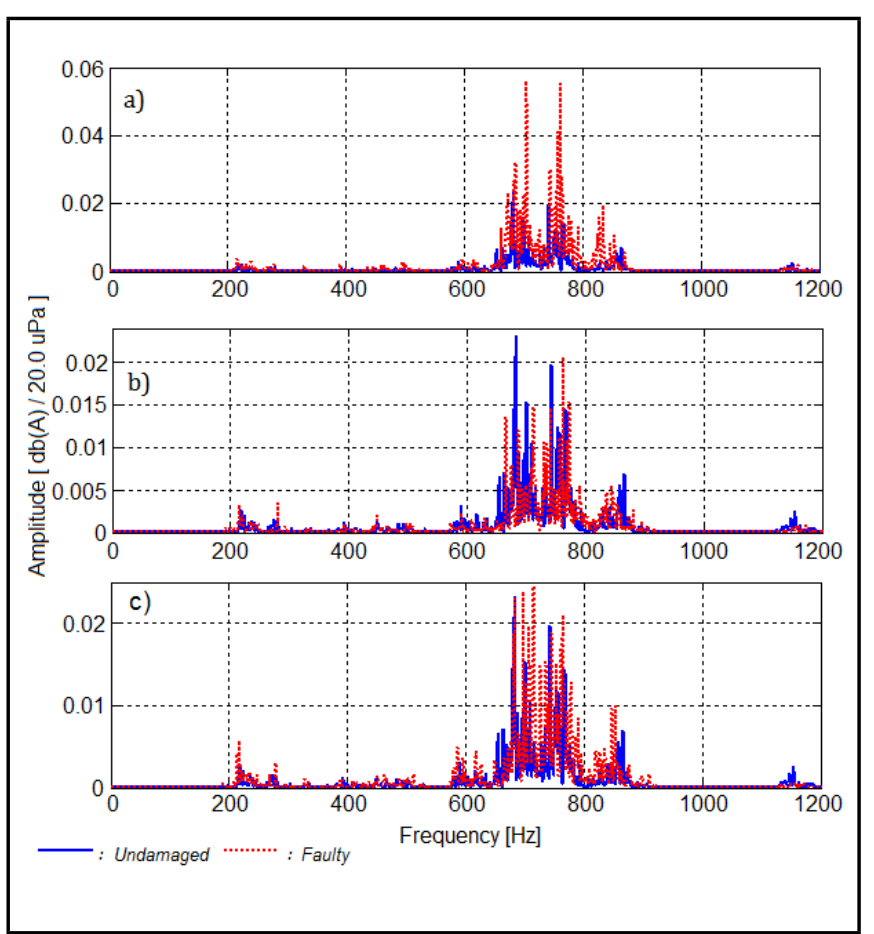

Figure 14. Pitting fault for spur gear at $500 \mathrm{rpm}$ rotation speed under (a) no loaded condition, (b) $1 \mathrm{Nm}$ loaded condition, and (c) $3 \mathrm{Nm}$ loaded condition.

tooth damage, such as cracks and pitting faults. One of the significant observations was the direct relation between AE level and loading conditions. From the statistical values, RMS of the SPL for both helical and spur gears is more consistent and sensitive. Increasing loading and running speed conditions for both gear types caused a change in RMS levels. Also, CF was measured at more than 6 , and indicated the damage with its high value in all cases. CF shows the damage severity in comparison with the changing RMS value of the signal. The RMS value of the sound signal changed with the loading conditions at the given frequency range. The loading condition affected the SPL of the gear, and AE peaks were observed at a higher sound level. For this reason, the increasing peak level/RMS ratio indicates a bigger $\mathrm{CF}$ value, which shows the severity of the local fault. Corresponding to the running speed of the gear, in general cases, an increasing speed increases the SPL of the signal. Gear defects, loading, and running speed increasingly affect the maximum and average values of the signal. All these statistical measurements confirm the existence of a fault in the gear system by comparing their reference value. Considering the gear types used in the measurements, it can be concluded that sound levels at helical gear meshing points are clearer, and maximum and average values of the fault signal are more apparent than that of spur gears.

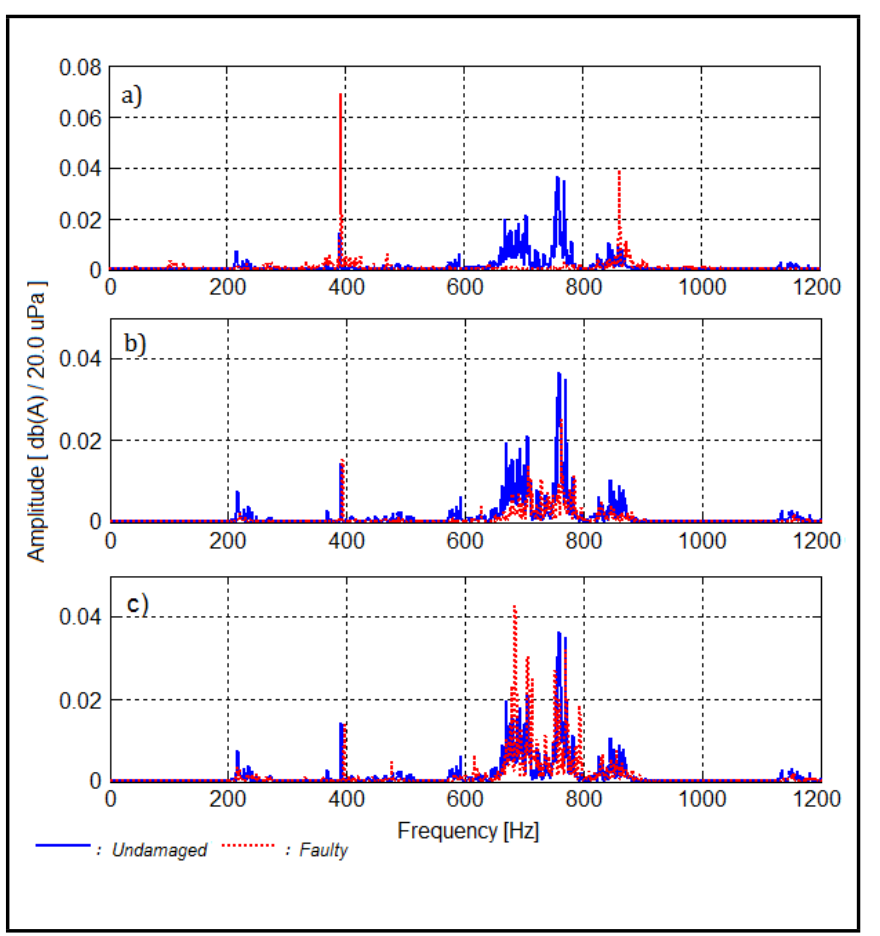

Figure 15. Pitting fault for spur gear at $700 \mathrm{rpm}$ rotation speed under (a) no loaded condition, (b) $1 \mathrm{Nm}$ loaded condition, and (c) $3 \mathrm{Nm}$ loaded condition.

\section{ACKNOWLEDGEMENTS}

This study is a part of the research project FBA-12-4111. The authors wish to express their thanks for financial support provided by the Scientific Research Projects Coordination Unit of Erciyes University, in carrying out this study.

\section{REFERENCES}

1 Husin, S., Mba, D., and Raja Hamzah, R. I. Viability of application of the acoustic emission (AE) technology for the process and management of maintenance in industries: defect detection, on-line condition monitoring, diagnostic and prognostic tool, Proceedings of the International Multi Conference of Engineers and Computer Scientists, 3, 978988, (2010).

2 Singh, A., Houser, D. R., and Vijayakar, S. Detecting gear tooth breakage using acoustic emission: a feasibility and sensor placement study, Journal of Mechanical Design, 21, 587-593, (1999). http://dx.doi.org/10.1115/1.2829503.

3 Eftekharnejad, B. and Mba, D. Seeded fault detection on helical gears with acoustic emission, Applied Acoustics, 70, 547-555, (2009). http://dx.doi.org/10.1016/j.apacoust.2008.07.006. 
${ }^{4}$ Mba, D., Cooke, A., Roby, D., and Hewitt, G. Detection of shaft-seal rubbing in large-scale power generation turbines with acoustic emissions; case study, Proceedings of Instution of Mechanical Engineers, Part A: Journal of Power and Energy, 218 (2), 71-81, (2004). http://dx.doi.org/10.1243/095765004773644076.

5 Metwalley, S. M., Hammad, N., and Abouel-Seoud, S. A. Vehicle gearbox fault diagnosis using noise measurements, International Journal of Energy and Environment, 2 (2), 357-366, (2011).

${ }^{6}$ Loutas, T. H., Kalaitzoglou, J., Sotiriades, G., Kayias, E., and Kostopoulos, V. Diagnosis of artificial gear defects on single stage gearbox using acoustic emission, Advanced Material Research, 13-14, 415-420, (2006). http://dx.doi.org/10.4028/www.scientific.net/amr.1314.415 .

7 Tan, C. K. and Mba, D. Correlation between acoustic emission activity and asperity contact during meshing of spur gears under partial elastohydrodynamic lubrication, Tribology Letters, 20 (1), (2005). http://dx.doi.org/10.1007/s11249-005-7793-1.

8 Tan, C. K. and Mba, D. Limitation of acoustic emission for identifying seeded defects in gearboxes, Journal of Nondestructive Evaluation, 24 (1), (2005). http://dx.doi.org/10.1007/s10921-005-6657-9.

9 Al-Balushi, K. R. and Samanta, B. Gear fault diagnosis using energy-based features of acoustic emission signals, Proceedings of the Institution of Mechanical Engineers, Part I: Journal of Systems and Control Engineering, 216-249, (2002). http://dx.doi.org/10.1243/095965102320005418.

10 Tan, C. K. and Mba, D. Identification of acoustic emission source during a comparative study on diagnosis of a spur gearbox, Tribology International, 38, 469-480, (2005). http://dx.doi.org/10.1016/j.triboint.2004.10.007.

11 Belsak, A. and Flasker, J. Method for detecting fatigue cracks in gears, Theoretical and Applied Fracture Mechanics, 46, 105-113, (2006). http://dx.doi.org/10.1016/j.tafmec.2006.07.002.

12 Belsak, A. and Flasker, J. Detecting cracks in the tooth root of the gears, Engineering Failure Analysis, 14, 1466-1475, (2007). http://dx.doi.org/10.1016/j.engfailanal.2007.01.013.

13 Combet, F., Gelman, L., and La Payne, G. Novel detection of local tooth damage in gears by the wavelet bicoherence, Mechanical Systems and Signal Processing, 26, 218-228, (2012). http://dx.doi.org/10.1016/j.ymssp.2011.07.002.
${ }^{14}$ Raja Hamzah, R. I. and Mba, D. The influence of operating condition on acoustic emission (AE) generation during meshing of helical and spur gear, Tribology International, 42, 3-14, (2009). http://dx.doi.org/10.1016/j.triboint.2008.06.003.

15 Baydar, N. and Ball, A. Detection of gear deterioration under varying load conditions by using the instantaneous power spectrum, Mechanical Systems and Signal Processing, 14 (6), 907-921, (2000). http://dx.doi.org/10.1006/mssp.1999.1281.

16 Baydar, N. and Ball, A. A comparative study of acoustic emission and vibration signals in detection of gear failures using Wigner Ville distribution, Mechanical Systems and Signal Processing, 15 (6), 1091-1107, (2001). http://dx.doi.org/10.1006/mssp.2000.1338.

17 Dempsey, P. J. A comparison of vibration and oil debris gear damage detection methods applied to pitting damage, NASA/TM-2000-210371, NASA Glenn Research Center, (2000).

${ }^{18}$ Decker, H. J. Crack detection for aerospace quality spur gears, NASA/TM-2002-211492, NASA Glenn Research Center, (2002).

19 Blunt, D. M. and Keller, J. A. Detection of fatigue crack in a UH-60A planet gear carrier using vibration analysis, $\mathrm{Me}$ chanical Systems and Signal Processing, 20, 2095-2111, (2006). http://dx.doi.org/10.1016/j.ymssp.2006.05.010.

${ }^{20}$ Guangzhong, C. Acoustical measurement and fan fault diagnosis system based on LabVIEW, Practical Applications and Solutions Using LabVIEW Software, Folea S., Ed., InTech, (2011), 11, 229-252.

${ }^{21}$ Miller, R. K. and Intire, P. Nondestructive Testing Handbook, Vol. 5: Acoustic Emission Testing, American Society for Nondestructive Testing, (1987), $2^{\text {nd }}$ edition.

22 Stewart, R. M. Some useful analysis techniques for gearbox diagnostics, Technical Report MHM/R/10/77, Institute of Sound and Vibration Research, University of Southampton, (1977).

${ }^{23}$ Dron J. P., Bolaers, F., and Rasolofondraibe, I. Improvement of the sensitivity of the scalar indicators (crest factor, kurtosis) using a de-noising method by spectral subtraction: application to the detection of defects in ball bearings, Journal of Sound and Vibration, 270, 61-73, (2004). http://dx.doi.org/10.1016/s0022-460x(03)00483-8.

24 Tandon, N. A comparison of some vibration parameters for the condition monitoring of rolling element bearings, Measurement, 12, 285-289, (1994). http://dx.doi.org/10.1016/0263-2241(94)90033-7. 